Der folgende Text wird über DuEPublico, den Dokumenten- und Publikationsserver der Universität Duisburg-Essen zur Verfügung gestellt.

Diese Version der E-Publikation ist kein Verlagsangebot und kann von einer eventuell ebenfalls veröffentlichten Verlagsversion abweichen.

Oades, Robert D.; : Zimmermann, Brigitte; : Eggers, Christian:

Conditioned blocking in patients with paranoid, non-paranoid psychosis or obsessive compulsive disorder : associations with symptoms, personality and monoamine metabolism.

http://duepublico.uni-duisburg-essen.de/servlets/DocumentServlet?id=25365

Quelle: In: Journal of Psychiatric Research, vol. 30 (1996) ; no. 5, p. 369-390 ISSN: 1879-1379 doi:10.1016/0022-3956(96)00006-4 


\title{
CONDITIONED BLOCKING IN PATIENTS WITH PARANOID, NON-PARANOID PSYCHOSIS OR OBSESSIVE COMPULSIVE DISORDER: ASSOCIATIONS WITH SYMPTOMS, PERSONALITY AND MONOAMINE METABOLISM
}

\author{
R. D. OADES, B. ZIMMERMANN and C. EGGERS \\ University Clinic for Child and Adolescent Psychiatry, Virchowstrasse 174, D-45147 Essen, Germany
}

\begin{abstract}
Summary-Conditioned blocking (CB) refers to a delay in learning that a new stimulus, added during learning, has the same consequences as the conditioned stimulus already present. In animals such "learned inattention" depends on monoaminergic and limbic function and, thus, CB performance should be informative on selective information processing impairments found in subgroups of psychotic patients. Attenuated CB in acute schizophrenia has been reported to normalize rapidly. This study examines in young patients the specificity of CB performance to illness, and its associations with symptoms, personality traits and monoaminergic metabolic status. CB was attenuated in psychotic patients with non-paranoid symptoms (NP: $n=12$, mean age 17 years) with respect to obsessive-compulsive (OCD: $n=13$, mean age 16 years) and healthy subjects (CON, $n=29$, mean age 18 years), but only a transient attenuation was observed in paranoid hallucinatory patients ( $\mathrm{PH}$ : $n=14$, mean age 19 years). Outgoing personality traits in CON and OCD subjects correlated with CB. In NP patients attenuated CB was associated with increasing neurotic lability. In PH patients CB correlated positively with "manic" but negatively with psychotic or neurotic scores. The severity of negative symptoms in psychosis and specific negative/positive symptoms in the NP/PH groups was associated with reduced CB. Increased dopamine activity (24-h urine samples) correlated positively with CB, but relative increases of noradrenaline metabolism in NP and serotonin metabolism in OCD patients interfered. In summary, marked psychotic or neurotic traits and some symptom-states were associated with reduced $\mathrm{CB}$. The particular selective processing problems of NP patients may reflect inappropriate NA activity.
\end{abstract}

\section{Introduction}

Latent inhibition (Lubow \& Moore, 1959) and conditioned blocking (CB, Kamin, 1969) belong to a paradigm known as learned inattention. If a stimulus (e.g. a light flash) is repeated several times without consequence before becoming associated with reinforcement, learning about the relationship initially occurs more slowly than without the non-reinforced preexposure. This is known as latent inhibition. If the flash is reinforced initially and during the course of learning a second stimulus is introduced (e.g. a tone, also perfectly correlated with reinforcement) then learning about the tone is initially slower than if the two stimuli were contiguous from the start. This is known as CB. In this paper we ask what can studies of learned inattention tell us about information processing in psychotic patients?

Learned inattention has been related to monoaminergic and limbic function (accumbensseptum-hippocampus and prefrontal cortex) in animals and its disruption in acute schizo- 
phrenia to a breakdown between monitoring attention-related activity and endogenous thought or motor programs (Gray et al., 1990).

Selective attention processing has long been described as impaired in psychotic patients (Shakow, 1936) but descriptions of the psychological or neurobiological mechanisms responsible have remained elusive (Oades, 1982). However as some patients (e.g. with paranoid hallucinatory symptoms) have a more tractable form of illness (i.e. better prognosis) and respond better clinically to neuroleptic medication (Straube \& Oades, 1992) we hypothesized that a subgroup analysis of CB performance in terms of active symptoms and monoaminergic metabolic status might reveal features on which this cognitive adaptiveness depends. The nature of these is, in part, predicted by the results of animal studies of learned inattention.

In animals, latent inhibition is disrupted by amphetamine and facilitated by haloperidol after acute/subchronic systemic treatment (Solomon et al., 1981; Weiner et al., 1988; Feldon \& Weiner, 1991). Local mesolimbic dopaminergic (DA) stimulation also disrupts (Solomon \& Staton, 1982). Serotonergic (5HT) activity in the raphe-hippocampal system has been implicated (Solomon et al., 1978; 1980; Cassaday et al., 1993) and noradrenergic (NA) function has been found to be relevant to the contextual sensitivity of latent inhibition (Mohammed et al., 1986; Honey \& Good, 1993). Many studies have implicated the anatomical substrates of the hippocampus and nucleus accumbens (Ackil et al., 1969; Schmajuk et al., 1994; Tai et al., 1995). For rats an intact hippocampus is necessary for CB measured in different task forms (Solomon, 1977; Rickert et al., 1978) but lesion of the dorsal NA bundle rather than ascending $5 \mathrm{HT}$ projections attenuates CB (Lorden et al., 1980). Indeed by pharmacologically changing the balance between $\alpha$ - and $\beta$-NA interactions, CB can be attenuated (Caza, 1984). The DA balance in mesolimbic and mesocortical areas is also important for the expression of $\mathrm{CB}$. Thus, amphetamine produces a haloperidol-reversible attenuation of CB (Crider et al., 1982) but haloperidol-induced DA supersensitivity reduces CB (Crider et al., 1986). Prefrontal 6-OHDA lesions that increase DA turnover disturb CB (Oades et al., 1987).

Learned inattention in healthy human subjects tends to be reduced if they show psychotic personality features. Latent inhibition attenuation has been reported in those with high psychoticism scores on the Eysenck (Baruch et al., 1988a) and MMPI scales (De la Casa et al., 1993). However, this reduction is sensitive to the personality scale used (Baruch et al., 1988a), experimental parameters (Lubow et al., 1992) and test form (Lipp \& Vaitl, 1992). However, for CB an initial report suggested that neurotic rather than psychotic features may lead to an attenuation (Jones et al., 1990). This raises the question of whether certain personality features are indicative of a trait contribution to psychopathological forms of information processing.

In an audiovisual test acute schizophrenics initially showed attenuated latent inhibition but normal performance in a later phase of the illness (Baruch et al., 1988b; Gray et al., 1992). This applied to paranoid and non-paranoid subtypes (Lubow et al., 1987). While the severity of symptoms probably played a role (Baruch et al., 1988b), these reports remain equivocal on the role of symptom-type and medication, which we would predict to be central to $\mathrm{CB}$ expression.

CB was examined by Jones et al. $(1990 ; 1992)$, first, in a visual reaction time paradigm 
with/without flanking letters. The distractors increased response times in controls and chronic schizophrenics but not the acutely ill; but an interaction with response made interpretation difficult. The second report using a complex audiovisual learning test confirmed an attenuation of $\mathrm{CB}$ in the acutely ill. Again the effect was stronger with increased symptom severity but it was confounded by a learning floor effect in the chronic patients.

We developed a visuospatial CB task-form (Oades et al., 1996) in which we compare the relationship of $\mathrm{CB}$ to personality, the types of symptom and their severity (correlational and subgroup analysis). Learning measures were also studied to try to discern if the type of task-solving strategy used related to CB. Pertinent here are reports that subjects with an outgoing personality perform better in situations requiring parallel processing (Eysenck, 1982, pp. 128-129), likely in this form of CB, and they may show quantitative differences of monoamine metabolism (e.g. low 5HT activity: Linnoila et al., 1983; Schalling et al.. 1984). Hence the relationship of performance to medication and the status of monoamine metabolism (urine samples) was studied. Thus, high levels of 5HT metabolism might be expected to interfere with $\mathrm{CB}$, but the relationship of catecholamine metabolism to $\mathrm{CB}$ is less easy to predict. An increase of DA metabolism might be expected to be beneficial in healthy subjects on the basis of metabolite increases and improved learned inattention following neuroleptic treatment of animals. However, patient responses may differ in view of illness-related differences in DA and NA activity and medication response. An initial report found $\mathrm{CB}$ attenuated in young NP rather than $\mathrm{PH}$ schizophrenics and to be associated with increased DA utilization (Oades et al., 1992).

The question of specificity was approached by including OCD patients. The OCDpsychosis comparison is of interest because of the implication of related frontal pathology (e.g. orbito-frontal vs prefrontal) and monoaminergic dysfunction (5HT vs DA) in both groups: they both show impaired attention-related information processing (reviews in Reed, 1985; Insel, 1992; Straube \& Oades, 1992) and psychosis not infrequently develops through an obsessive phase in adolescence (Eggers, 1968; Eisen \& Rasmussen, 1993).

\section{Methods}

\section{Subjects}

From 30 consecutive admissions for schizophrenia-like psychosis ( $\mathrm{SCH}$ ), 26 in-patients learned the CB task; three did not achieve the learning criterion and the data for another were lost. Diagnosis (DSM-III-R) was made by the senior therapist, two psychologists and a clinician who also rated a semi-structured interview on tape. Diagnostic subtypes included: 12 paranoid (295.3), four disorganized (295.1), two undifferentiated (295.9), one residual (295.6), four schizoaffective (295.7), two reactive (298.8) and one atypical (298.9). Further diagnoses were not made. Exclusion criteria included other major illnesses, substance abuse and a performance IQ under 70 (Ravens standard progressive matrices, Table 1).

Psychotic patients were interviewed for the assessment of positive and negative symptoms over the week of the tests (Andreasen, 1983, 1984: for four raters and all 64 questions, Spearman $\rho$ ranged from .64 to .75 between subjects). A subgroup of paranoid-hallucinatory patients $(\mathrm{PH})$ was separated on a median split (score of 7) on the scores for delusions and hallucinations from the remaining non-paranoid group (NP). (Group num- 
Table 1.

Group Comparisons for Age, Gender, Stage of Illness, Perceptuomotor Ability and Medication (Mean and SD)

\begin{tabular}{|c|c|c|c|c|c|c|c|c|c|}
\hline & & $\begin{array}{c}\text { Age } \\
\text { (years) }\end{array}$ & $\begin{array}{l}\text { Gender } \\
\mathrm{m}\end{array}$ & $\mathrm{f}$ & $\begin{array}{c}\mathrm{SCH} \\
\text { episode } \\
\text { OCD } \\
y\end{array}$ & $\begin{array}{c}\text { SPM } \\
\text { IQ }\end{array}$ & & $\begin{array}{c}\text { GFT } \\
\text { neurol. } \\
\text { T score }\end{array}$ & $\begin{array}{c}\text { Medication } \\
\text { CPZ } \\
\text { equivalents }\end{array}$ \\
\hline $\mathrm{SCH}$ & $n=26$ & $\begin{array}{r}18.4 \\
3.6\end{array}$ & 14 & 12 & ${ }_{1.6}^{2.0}$ & 89 & 15 & $\begin{array}{ll}49 & \end{array}$ & ${ }^{935}{ }_{1067}$ \\
\hline & $n=14$ & $\begin{array}{c}19.3 \\
3.6\end{array}$ & 8 & 6 & ${ }_{1.8}^{2.4}$ & 91 & 16 & $\begin{array}{l}49 \\
10\end{array}$ & 899 \\
\hline$-\mathrm{NP}$ & $n=12$ & ${ }_{1.0}^{17.3}$ & 6 & 6 & $\begin{array}{l}1.8 \\
1.2\end{array}$ & 87 & 14 & 70 & $\begin{array}{l}978 \\
\quad 1397\end{array}$ \\
\hline OCD & $n=13$ & $\begin{array}{r}16.3 \\
2.9\end{array}$ & 9 & 4 & ${ }^{2.3} 1.8$ & 118 & 21 & $42 \quad 10$ & - \\
\hline $\mathrm{CON}$ & $n=29$ & $\begin{array}{l}18.0 \\
3.6\end{array}$ & 15 & 14 & - & 113 & 15 & $\begin{array}{ll}38 & \end{array}$ & - \\
\hline
\end{tabular}

There were no significant age differences. $\mathrm{CPZ}=$ chlorpromazine equivalents (Rey et al., 1989); two patients were medication free; there was no significant difference between subgroups. Episode $=$ number of admissions including the current stay ( 15 patients were in their first episode). OCD y=duration in years. GFT =Göttinger Form Test (copy figures: scores $<40$ normal, $>60$ suspected brain damage). SPM $=$ Raven's standard progressive matrices (performance IQ). SCH patients had lower SPM and higher GFT scores than OCD $(t=4.8 /-2.3$, $p<.01 / .03)$ and CON subjects $(t=5.7 /-5.0, p<.0001)$.

bers of 14 and 12 reflect two patients with the median score.) $\mathrm{PH}$ patients also showed more thought disorder and bizarre behaviour (see results below). Brief psychiatric ratings of symptom severity were obtained (Overall \& Gorham, 1962).

Thirteen non-medicated OCD in-patients (300.3, DSM-III-R) had no comorbid diagnoses except for one case of trichotillomania. From 56 healthy subjects (aged 8-26 years) 26 were paired with each psychotic patient matching for gender and for age, within 4 months. Three more subjects were added to match the three youngest OCD patients. These controls reported no psychiatric complaints or major medical problems and were free of medication when tested (CON in Table 1).

Testing followed: (a) approval of the protocol by the clinic management; (b) agreement of the therapists and nursing staff to the tests in principle and the time-point in each case; and (c) the co-operation, understanding and consent of the adult or child and the legally responsible adult.

\section{CB task}

CB was measured in a learning task presented on a pc colour monitor with a joystick for response. This "mouse-in-house" game took 5-20 min to perform (described in Oades et al., 1996; software obtainable from the first author). A brief description follows.

A $13 \times 24 \mathrm{~cm}$ rectangle was presented as a "house", divided into two "rooms" by a wall with a door in the centre. Each room was divided into four by walls, through which the mouse could not go. One to three colour panels $(18 \times 7 \mathrm{~mm})$ appeared above in the middle at the start of each trial. Small panels displayed the minus and plus points scored during the task (Figure 1). 


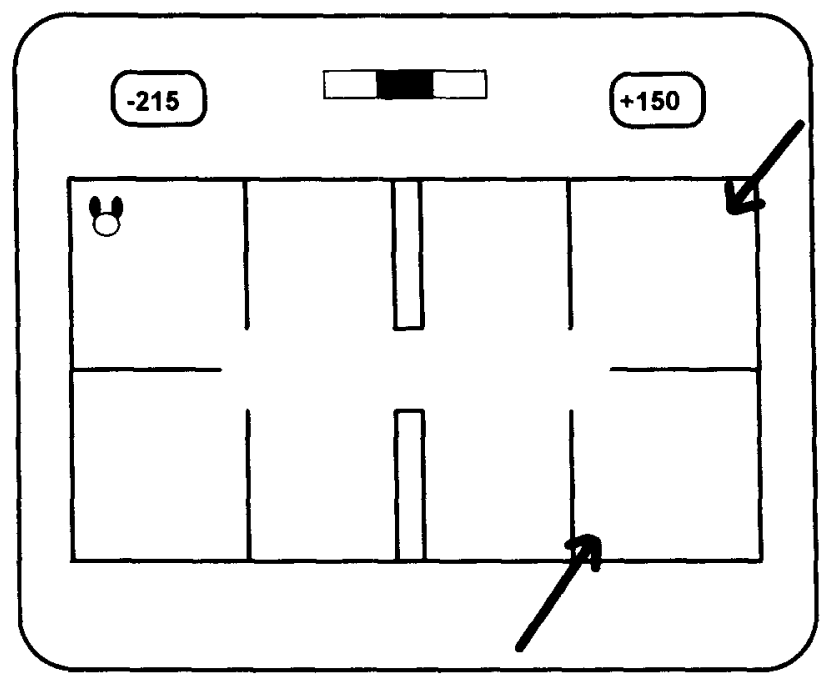

Figure 1. Schematic drawing of the task situation for measuring conditioned blocking: a "house" is divided into two rooms, each with walls that the mouse-cursor (upper-left) cannot cross. Three colour cue panels appear (upper middle) and the subject searches for a safe-spot (e.g. lower arrow). The subject is awarded +15 points (upper right) on reaching this goal. Delays are awarded minus points (upper left). The upper arrow (right) indicates an alternate mirror-image starting point for one of the two conditioning tasks.

\section{Task procedure}

Testing started between 9:00 and 11:00 a.m. with 1 day between the first $(A)$ and the second sessions (B). A was the subject's own learning control session and B was the blocking test session. Subjects were instructed to bring the mouse-like cursor to one of two possible "safe spots", demonstrated during joystick calibration. The safe-spot would shimmer yellow and +15 points were awarded (inter-trial interval, $2 \mathrm{~s}$ ). The mouse might start in either room and the goal was always in the other room.

At the start of each trial one of two sets of colour panels lit up for $1 \mathrm{~s}$. These sets were cues as to which of the two safe-spots was the goal on a particular trial. In A (phase 1) there was a set of three colours throughout training. Subjects were warned to attend to these. If they did not reach the goal within $8 \mathrm{~s}$ they got 5 minus points for each additional second. When subjects had reached the learning criterion ( $88 \%$ in eight trials without minus points), they proceeded to 21 test trials when the first and third colours were presented alone for response (alternately first-third and third-first from each colour set). The main measure was the latency to find the goal after the colour originally presented on the right minus that on the left. Data for the first test trial were discarded due to the inevitable surprise of seeing only one colour cue.

Session B, presented $48 \mathrm{~h}$ later, started with one of two pairs of colours. After achieving a $50 \%$ criterion over eight trials (B phase 1 ) a third colour was added until the full learning criterion had been reached (B phase 2). CB would be expected in the response latency to the third (added) colour when presented alone in the test phase with respect to the first colour (alone), seen from the start of the session. The start positions to the same colour set 
alternated from side to side while the colour sets were presented in a pseudo-random sequence.

$\mathrm{CB}$ was measured by comparing the differential response latencies in $\mathrm{A}$ and $\mathrm{B}$ [i.e. B test (third minus first stimulus) minus $A$ test (third minus first stimulus). This was calculated for the first pair of test stimuli, BA 1; the mean of the first three pairs, BA 1-3; five pairs, BA 1-5; all 10 pairs of stimuli, BA 1-10; and the first vs the last three test trials on B (B13)-(B8-10)]. Positive scores show CB or in the last case the development of "unblocking".

\section{Personality measures}

Personality traits were rated on the Minnesota Multiphasic Personality Inventory in 33 subjects over 16 years old (MMPI, 221 questions: Gehring \& Blaser, 1982), and the Hamburg Neuroticism Extroversion Scale with norms up to 16 years of age was used for all subjects to provide continuity across adolescence (HANES, 68 questions: Buggle \& Baumgürtel, 1975).

The MMPI scales studied were social introversion (SI), paranoia (PA), depression (D), psychopathy (PD), psychasthenia (PT), schizophrenia (SC) and hypomania (MA). Attention was also paid to the clinical use of three neurotic features (hypochondria, D and SI) and purported indicators for psychopathologic (4-9, PD/MA) or schizotypal personalities (2-7-8, D/PA/SC; 8-9, SC/MA; Merritt \& Balogh, 1990). We focus on single HANES scales, scored 1-9, as indicators of emotional lability ("neuroticism"; N1), need and ability to be sociable (E1) and outgoing activity (sensation seeking; E2). The HANES extroversion measures correlated negatively with MMPI SI alone (e.g. E1, $r=-.64, p=.008$ ), and the HANES neuroticism scores correlated positively with PT, SI, D, the sum of the three neurotic dimensions, the schizotypal $2-7-8$ scale but with no other dimensions $(r=.52-.72$, $p=.04 .002$ ).

\section{Urine collection}

DA, NA, 5HT and their metabolites (homovanillic acid, HVA; 3-methoxy-4-hydroxyphenyl-glycol, MHPG; 5-hydroxyindoleacetic acid, 5HIAA) were measured in 24-h urine collections (low monoamine diet) on the day between tests A and B. Acidified samples were frozen until analysis with ion-exchange liquid chromatography and fluorescence detection. Volume-adjusted measures were expressed as $\mathrm{ng} / \mathrm{g}$ creatinine per $\mathrm{m}^{2}$ body area to correct for general somatic metabolic rates and large variations of body size (see Oades et al., 1994).

\section{Data treatment}

Two-way MANOVAs (a precaution against intersubject variability) were used to study (a) learning measures in the different task phases and (b) CB between subject groups: repeated measures were used where related CB measures were studied. Significant results were followed by one-way ANOVAs and post-hoc Newman-Keuls tests, cited in the text, to determine where the significance lay. Correlation coefficients (Pearson $\rho$ ) were calculated between learning and $\mathrm{CB}$ measures as an indication of the task-solving strategy used. Bonferroni $\alpha$-corrections are described in the text to guide the interpretation of significance. 
Insignificant interactions $(p>.1)$ are not reported but the terms "tendency, trend and tend" refer to significances of $p=.05-1$.

An iterative procedure was adopted for the study of symptom, personality and monoamine measures (cf. Swerdlow et al., 1995). After performing analyses of variance for group differences, Pearson correlation coefficients were calculated between individual scores and CB measures. Then hypotheses based on the correlations were examined by linear (and stepwise) regression using the dependent measures of $\mathrm{CB}$ shown to be useful and partial correlations cited.

\section{Results}

\section{Conditioned blocking $(C B)$ and learning}

Learning. First learning measures are examined for the potential confound with interpretations in terms of blocking and illumination of the potential group differences in learning strategy.

Both comparison groups required a similar number of trials to learn tasks A and B. An increased number of trials for the psychotic vs the comparison groups was consistent across each learning phase (Newman-Keuls, $p<.007$; Figure 2, left). The removal of outliers $(>3 S D)$ decreased means for NP (not PH) patients by $8 \%$. In each phase of learning, PH patients needed more trials than both comparison groups, but the effect was less marked for the NP group.

Exploration search-times (punished with minus points) showed a similar pattern. Psychotic patients spent about three times as long exploring as the others $(.04<p<.0001)$. The PH group explored for longer than the two comparison groups $(p<.003)$ and again the effect was less marked for NP patients (Figure 2, middle). Both subgroups spent about
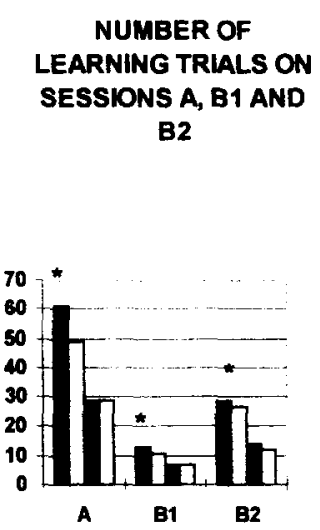

EXPLORATION TIME (seC) DURING LEARNING (sessions A, B1 and B2) AND DURING THE TEST PHASES (Atost 8 B-tast)

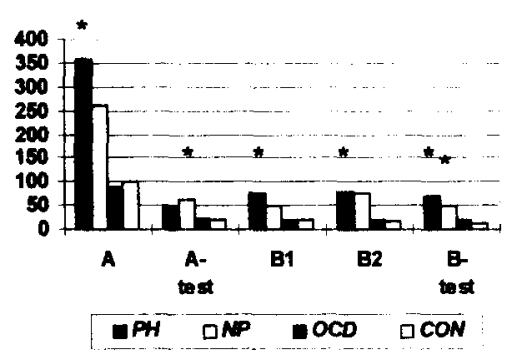

LENGTH OF SESSION $A$ and $B$ (min)

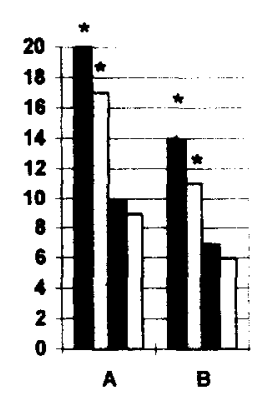

Figure 2. Three learning session measures before testing for CB. ANCOVA for four subject groups with IQ as covariate (Newman-Keuls post-hoc tests). (Left) Learning trials $=F(9,136)=2.84, p=.004$; *in each session $\mathrm{PH}>\mathrm{OCD}$ and CON $p<.002, \mathrm{NP}>\mathrm{CON} p<0.03$. (Middle) Exploration time $=F(15,149)=2.31, p=.006$; $*$ in each phase $\mathrm{PH}>\mathrm{OCD}$ and $\mathrm{CON} p<0.003$, A-phase NP $>$ CON, B-phase also NP $>$ OCD $p<0.03$. (Right) Task length $=F(6,112)=5.34, p=.0001, \mathrm{PH}$ and $\mathrm{NP}>\mathrm{OCD}$ and $\mathrm{CON} p<0.007, \mathrm{PH}>\mathrm{NP} p<.01$. 
twice as long on sessions A and B as the others, with the PH needing more time than the NP group (Figure 2, right).

Correlations between these "learning measures" for each group provide an indication of the differences of task-solving strategy used. Most correlations were highly specific to the phase of learning for each subject group (e.g. trials and exploration time on $\mathrm{A}, r=+.77$ $.92, p<.0001$; trials on $\mathrm{B}$ phase ii and duration $r=+.69-.84, p=.01-.0001$ ). Measures on sessions $\mathrm{A}$ and $\mathrm{B}$ did not correlate with two exceptions: for $\mathrm{PH}$ alone, $\mathrm{A}$ and $\mathrm{B}$ test exploration times correlated $(r=+.80, p=.001)$ and for NP alone the number of learning trials on the two three-stimuli phases correlated $(r=+.78, p=.003$ : see Discussion).

Examination of the contribution of psychopathology to slower learning in psychotic patients showed no correlation with negative or positive symptom ratings. Brief psychiatric ratings for positive, negative or psychotic symptoms and HANES personality ratings were not related to any learning measure. However, a clear relationship was found between an increased number of trials on the three-stimuli phase of session B and MMPI scores for neuroticism (3 Ns), psychopathy (4-9) and schizotypy $(2-7-8,8-9: n=33, r=+.59-.67$, $p<.0001$; significant with $\alpha$-correction). There were similar correlations with exploration and duration in the final learn and test phases.

\section{Conditioned blocking $(C B)$}

A CB effect for controls and OCD patients of about $4 \mathrm{~s}$ on the first trial pair decreased across the test session with learning about the added stimulus (Figure 3). A MANOVA was performed with repeated measures to see which of five related measures of CB might show group differences $[F(8,260)=2.51, p=.012]$. The covariate of IQ proved to have a trivial effect on these measures $[F(8,256)=2.37 ; p=.018]$. Normal CB levels on each measure were reduced in the psychotic patients, but only significantly so for the first trial-pair comparison $(p<.0001)$. CB across trials $1-3$ and $1-5$ (the best CB measures in healthy subjects; Oades

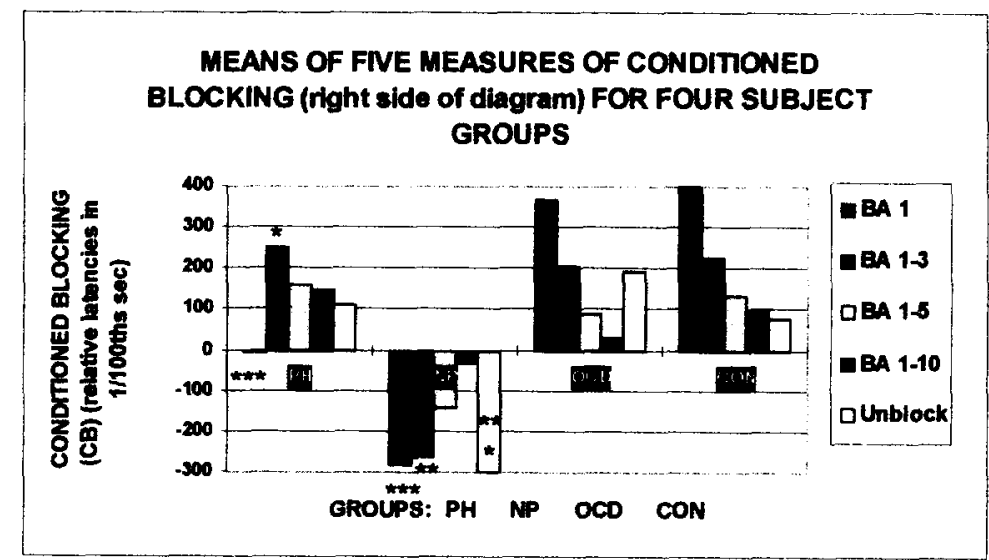

Figure 3. Normal CB scores are positive: for the comparison groups, on the right, CB decreased successively across test trials. On the left, PH and NP groups showed attenuated CB on the first trial $(* * * .0001<p<.01)(\mathrm{PH}$ vs $\mathrm{CON}, \mathrm{NP}$ vs $\mathrm{OCD}$ or $\mathrm{CON})$. NP continued to show reduced $\mathrm{CB}$ across trials $(* * .01<p<.05$ vs $\mathrm{CON})$. But $\mathrm{PH}$ showed normal CB from the three trial measure onwards ( ${ }^{*} p<.1$ vs NP on BA $1-3$ and unblocking). 
et al., 1996) correlated negatively with the ratio of negative to positive symptoms in the psychotic group $(n=23, r=-.62, p<.002)$. Subgroup performance on these measures was examined further.

An ANOVA with repeated measures for four CB measures [i.e. BA 1, BA 1-3, BA 1-5, unblocking $(F(9,141)=2.01, p=.04]$ gave a significant main effect for group $[F(3,60)=2.67$, $p=.05]$ and an interaction $[F(9,180)=2.3, p<.02$; Figure 3]. The main effect showed an average attenuation of $-2.5 \mathrm{~s}$ in the $\mathrm{NP}$ group vs an average CB effect in the other groups of +1.3 to $+2.4 \mathrm{~s}$.

On the first trial-pair post-hoc tests confirmed that NP patients showed less CB than either of the comparison groups and PH patients less than the controls. On BA 1-3 the NP showed less CB than the controls and tended to show less than the PH group (Figure 3). One-way analysis for unblocking $[F(3,60)=3.7, p<0.02]$ confirmed continuing less CB in the NP than in the PH, OCD and control groups. Thus, the PH group showed only a transient reduction of $C B$ on the first trial-pair, but the NP group had a marked deficit across measures. Even so, all groups demonstrated some learning about the added stimulus across the test exposure. The following sections consider the associations of these CB measures.

\section{Personality Traits and Symptom States}

\section{Associations with positive and negative symptom clusters}

Does a more consistent CB attenuation in NP than PH patients relate to a particular symptom cluster? Both groups showed a similar incidence of the five negative symptom clusters, but the PH group differed significantly on each of the four positive symptom clusters $[F(9,13)=2.7, p=.05$; Newman-Keuls, $p=.05-.001]$.

In psychotic patients, reduced $\mathrm{CB}$ correlated with an increase of the ratio of negative to positive symptoms (BA $1-3$, unblocking, $r=-.62$ to $-.67, p<.002$; significant after $\alpha$ adjustment). Within the NP group the negative relationship was maintained (BA 1, BA 13 and unblocking, $r=.65$ to $-.89, p=.03-.0001$. significant on $\alpha$-adjustment) but an opposite trend was seen in $\mathrm{PH}$ patients $(r=+.6, p=.05)$. The apparent paradox that negative symptoms were related to decreased CB in NP but to an increase in PH patients, is explained by specific negative symptoms being relevant in the NP group (flat-affect vs BA 1, $r=-.62, p=.04$; alogia vs unblocking, $r=-.69, p=.02$ ) but positive symptoms were important in the $\mathrm{PH}$ group (delusions vs $\mathrm{BA} 1-3, r=-.55, p=.06$; bizarre behaviour vs unblocking or BA $1-5, r=-.59$ to $-.65, p=.04-.02$, uncorrected levels of significance).

A linear regression analysis for the main $\mathrm{CB}$ measures vs the ratio of negative to positive symptoms for psychotic patients confirmed an attenuation of $\mathrm{CB}$ with increased negative symptoms (- -.65 to $-.89, p=.03-.0002)$. Analysis of separate symptom clusters was only significant for the first trial-pair measure. Extremes of positive and negative symptoms may interfere with normal CB (flat-affect -.90 , bizarre behaviour $-.66, p=.007$; hallucinations $+.54, p=.035$; thought disorder $+.63, p=.01)$.

Within the $P H$ group linear regression confirmed the influence of summed positive symptoms (BA $1-3,-.70, p=.03$ ). This was supported in the brief psychiatric ratings by a relationship with positive symptoms, absent for negative, depressive or sum scores (--.63. 
$p<.007)$. From a stepwise regression of clusters, bizarre behaviour stood out across measures (Figure 4). However, delusions also had a detracting influence on BA 1-3 scores $(-.82, p=.005)$ and flat-affect had a detracting influence on the first trial-pair measure (Figure 4A). For the NP group a linear regression was only significant for unblocking (Figure $4 \mathrm{~A}$ vs $4 \mathrm{~B}$ ), but the first step in a backward regression showed that flat-affect interfered with CB on the first trial-pair measure $(-.62, p<.04)$.

The opposing tendencies for different clusters in the analysis in Figure 4 might imply that their severity rather than their nature was important. This interpretation for performance on the first three trial-pairs was supported by the brief psychiatric ratings where total scores of illness severity, in contrast to component measures, had negative coefficients $(-.79$ to $-.89, p=.02-.002)$.

\section{Associations with personality features}

Having considered the contribution of symptom and state to the differences in information processing strategies of $\mathrm{PH}$ and NP patients, it is important now to take this approach further and to consider if these strategies are related to more deeply embedded characteristics of personality. Analysis of HANES features across all four groups showed: (a) more lability in $\mathrm{PH}$ (N1, vs CON and OCD, trend vs NP); (b) less need for sociability in $\mathrm{PH}$ (E1, vs NP and CON); and (c) the least extroversion in OCD (E2, vs CON and SCH: Table 2). As expected psychotic patients scored 10-20 points significantly above healthy controls on most MMPI measures.

For controls there were no correlations between HANES features and CB measures. Among MMPI, dimensions only deviate (PD) tendencies interfered (BA 1-3, $r=-.56$, $p=.03)$. HANES E2 extroversion features assisted CB in $O C D$ patients, notable for low E2

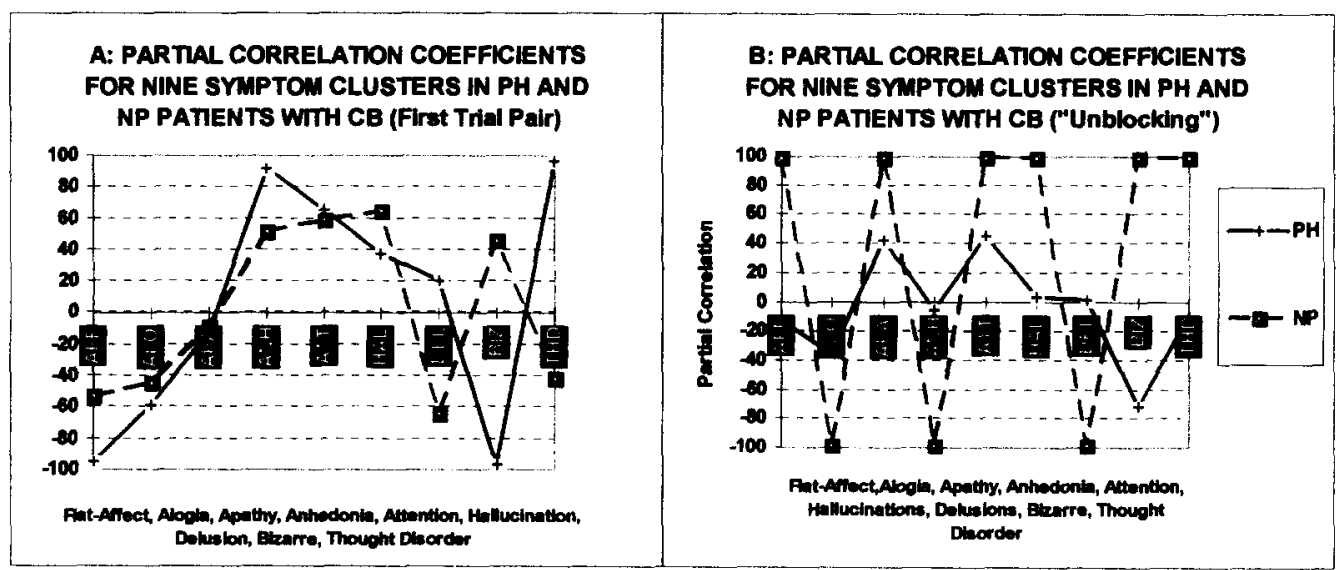

Figure 4. (A, left) A profile of partial correlations between negative and positive symptom clusters and the first trial-pair measure of CB which was decreased in both the PH and NP groups. There were no significant relationships for the NP group. For PH, flat-affect, anhedonia, bizarre behaviour, thought disorder, $.05<p<.01$. (B, right) A similar profile for the unblocking measure on which only the NP group showed attenuated CB. There was no significant relationship for the PH group. For NP, flat-affect, alogia, apathy, anhedonia, attention, bizarre, thought disorder; $p=.003-.0003$. 
Table 2.

Selected Personality Ratings for Psychotic (SCH), Obsessive-compulsive (OCD) and Healthy Subjects (CON) $(M E A N+\mathrm{SEM})$

\begin{tabular}{|c|c|c|c|c|c|c|c|c|c|c|}
\hline & \multicolumn{2}{|c|}{ HANES scales } & & \multicolumn{2}{|c|}{ MMPI scales < } & \multirow[b]{2}{*}{ PD } & \multirow[b]{2}{*}{ PA } & \multirow[b]{2}{*}{ PT } & \multirow[b]{2}{*}{$\mathrm{SC}$} & \multirow[b]{2}{*}{ MA } \\
\hline & N1 & E1 & E2 & SI & D & & & & & \\
\hline & & & & * & \# & \# & $\#$ & $\#$ & \# & \\
\hline \multirow[t]{3}{*}{ SCH } & 6.4 & 6.4 & 4.7 & 61.8 & 63.5 & 63.5 & 66.5 & 66.3 & 69.6 & 58.7 \\
\hline & -4 & -5 & -4 & 2.3 & 2.8 & 2.3 & 3.8 & 2.9 & 3.7 & 2.6 \\
\hline & $n=25$ & & & $n=13$ & & & & & & \\
\hline PH & $\begin{array}{r}7.1 \\
n=13\end{array}$ & 4.9 & 4.5 & $\begin{aligned} & 63.2 \\
n & =9\end{aligned}$ & 64.2 & 63.3 & 69.4 & 68.0 & 73.3 & 60.4 \\
\hline \multirow[t]{2}{*}{ NP } & $\begin{array}{r}5.7 \\
n=12\end{array}$ & 8.0 & 4.8 & $\begin{array}{r}57.7 \\
n=4\end{array}$ & 61.3 & 64.0 & 57.7 & 61.3 & 58.3 & 53.3 \\
\hline & & & & & & & ** & & $* *$ & \\
\hline \multirow[t]{2}{*}{$O(D)$} & 5.5 & 6.1 & 3.3 & 55.6 & 56.0 & 56.8 & 53.0 & 61.4 & 56.6 & 50.0 \\
\hline & $\begin{array}{r}-4 \\
n=13\end{array}$ & -8 & -5 & $n=5$ & 5.0 & 4.2 & 4.6 & 2.6 & 1.9 & 2.6 \\
\hline \multirow[t]{3}{*}{$\operatorname{CON}$} & 50 & 7.6 & 5.2 & 49.0 & 47.9 & 48.6 & 46.5 & 48.9 & 50.5 & 51.8 \\
\hline & -4 & -2 & -4 & 2.4 & 2.0 & 1.5 & 1.7 & 2.5 & 1.4 & 2.4 \\
\hline & $n=29$ & & & $n=16$ & & & & & & \\
\hline
\end{tabular}

Scores significantly deviant from controls are in bold. HANES (three group analysis: SCH, OCD. CON) $F(6,124)=2.9, p=.012$; Newman-Keuls, .01<p<.04; $(\mathbf{N 1}, \mathrm{SCH}>\mathrm{CON}$ and E1, SCH $<\mathrm{CON}$, and E2, $\mathrm{OCD}<\mathrm{SCH}$ and $\mathrm{CON}$ ); (four group analysis: $\mathrm{PH}, \mathrm{NP}, \mathrm{OCD}, \mathrm{CON}) F(9,148)=4.17, p<.0001$; Newman-Keuls, $.05<p<.001$ (N1, PH $>$ CON; E1, PH $<$ NP \& CON; E1 \& E2, OCD $<$ CON). MMPI (three group analysis: SCH, OCD, CON) $F(14,46)=2.62, p=.007$; Newman-Keuls, $p<.02 \mathrm{SCH}$ vs CON, ${ }^{*}$ vs OCD: ${ }^{+} p<.002$. SCH vs CON For abbreviations see Methods section.

scores (e.g. on first trial-pair, $r=+.81, p=.002$, uncorrected). However, NP and PH patients showed contrasting associations. Increased lability $(\mathrm{N} 1)$ correlated with $\mathrm{CB}$ in the NP group (three CB measures, $r=+.59-.66, p=.04-.02$ ), but on the only measure where $\mathrm{PH}$ had attenuated CB (first trial-pair), CB related to decreased lability $(r=-.60, p=.03)$ with a similar modest relationship to psychasthenia $(r=-.6, p=.07$ uncorrected $)$.

A linear regression with all HANES features confirmed that CB related to decreased neurotic lability in the PH and to an increase in the NP group on the initial trial-pair measure (when both showed reduced CB; Figure 5). On the three-trial measure and unblocking where only NP patients showed attenuated $\mathrm{CB}$, their relationship with lability was maintained $(+.72$ and $+.8, .002<p<.02)$ and that for PH patients was lost $(-.34, p=.31)$.

MMPI data were too sparse for analysis in NP or OCD groups, but in the $\mathrm{PH}$ group they help to explain the development of CB absent in the NP group (Table 2). For the main $\mathrm{CB}$ measures negative partial correlations for the " $3 \mathrm{Ns}$ " (neuroticism; $-.79, p=.02$ ) and schizophrenic features (SC, -.94$)$ tend to be opposed by manic features (MA, $+.95, p<.1$ ). Thus, while neurotic and psychotic features, more evident in $\mathrm{PH}$ patients, may interfere with normal CB at first, their influence may be overcome by manic tendencies (less evident in NP patients, Table 2). There were no clear MMPI relationships with CB performance in the controls.

The Status of Monoamine Activity

One interpretation of these data is that the PH and NP groups differ according to another feature that is associated with the positive-negative symptom distinction in general but is 


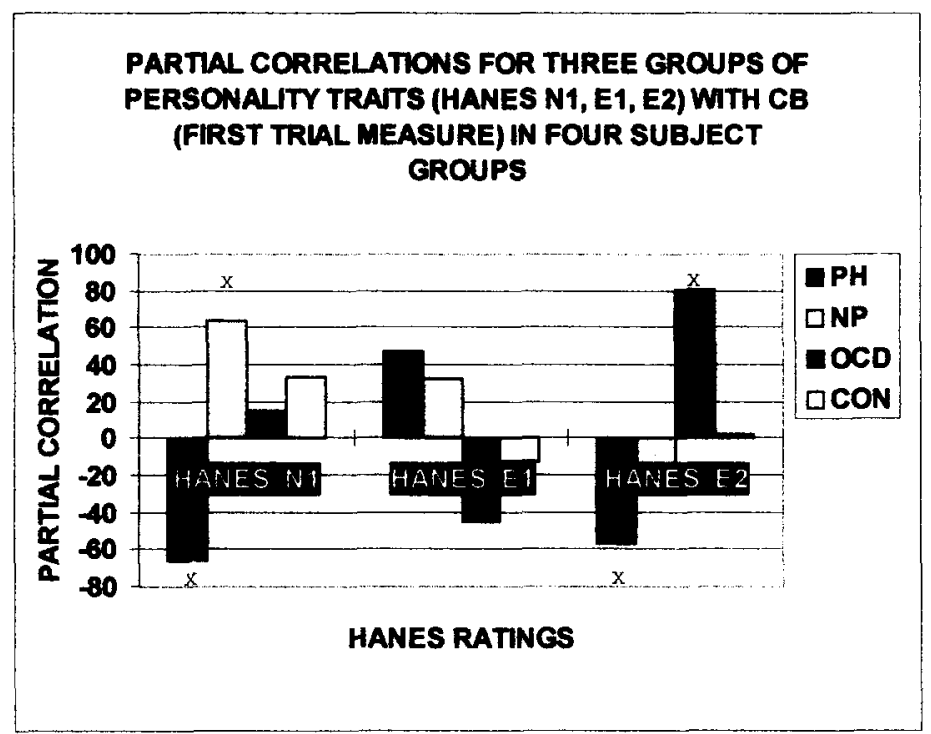

Figure 5. Partial correlations from a linear regression of HANES personality traits with the first trial CB measure. Increases of N1 (neuroticism and lability) in the NP group $(p=.04)$ and E2 (outgoing extroverted activity) in the OCD group were associated with increased CB $(p=.002)$. In $\mathrm{PH}$ patients decreased CB was associated with increases of $\mathrm{N} 1(p=.025)$ and $\mathrm{E} 2(p=.063)$.

not described by a particular symptom. This section examines whether monoamine activity and the effects of medication are appropriate candidates. Briefly, the biochemical analysis (see Oades et al., 1994) showed high levels of utilization (metabolite/monoamine) in PH and NP vs comparison groups for DA, NA and 5HT, where DA utilization tended to be higher in PH patients. OCD patients showed increased levels of adrenalin, HVA, 5HT and 5HIAA.

\section{Medication}

Neuroleptic doses did not correlate with CB or biochemical measures, except for an increase in HVA and the HVA/5HIAA ratio in the $\mathrm{PH}$ group alone $(r=+.58, p=.04)$. Of five patients taking clozapine (four in the PH group) two showed good CB and two showed some attenuation. These patients did not show increased NA utilization as might be expected from $\alpha-2$ anatagonism. However, two patients on propranolol had high MHPG levels and were excluded from the analysis. Patient groups did not differ significantly on anticholinergic medication [biperidine: $\mathrm{PH}, n=8$, mean $4.3 \mathrm{mg}(S D=1.7 \mathrm{mg})$; NP $n=6$, mean $5.3 \mathrm{mg}(S D=1.6)]$. However, as dose tended to relate to BA 1-3 and BA 1-5 $(r=+.46-.51, .05<p<.1)$ a cholinergic influence on CB should not be overlooked.

\section{Associations with Monoamine Metabolism}

Among adrenergic measures only NA utilization (MHPG/NA) correlated with any CB measure (CON alone, BA 1 and BA $1-3, r=+.52-.42, p=.01-.02$ ). However, in OCD 
patients, who showed lower NA metabolism than any other group, decreasing NA utilization tended to be associated with increasing CB (BA 1-3, unblocking; $r=-.5$ to -.6 , $.1<p<.05$ ). 5HT utilization (5HIAA/5HT) tended to increase with decreased $\mathrm{CB}$ on the unblocking measure alone in the OCD group $(r=-0.58, p<.06)$. In view of the widespread finding of unusual 5HT (and sometimes DA) activity in OCD patients, the correlation of unblocking with increased HVA/5HIAA is of interest (Figure 6).

There were a number of correlations for the status of DA metabolism and its relation to NA and 5HT metabolites (Figure 6). In controls increasing DA metabolism and its relation to NA metabolism was associated with increased CB. For OCD patients the relationship to HVA was less marked, but like the control group an increase with respect to NA metabolism correlated with $\mathrm{CB}$. In contrast, the NP group showed a negative association with HVA/MHPG (Figure 6). CB did not clearly relate to any biochemical measure in the PH group (but see Figure 6).

Pursuing these correlations in a linear regression for the four HVA and HVA ratio measures supports a major role for DA metabolism in the $\mathrm{CB}$ shown by controls. The utilization measure alone was significant $(+.65, p=.001)$. Stepwise regression for three $C B$ measures leaving DA utilization in the equation attained $5 \%$ significance or better (BA 1 , +.63 ; BA $1-3,+.40)$. In OCD patients linear regression showed that the significance of NA or 5 HT metabolism relative to DA was lost with their HVA/metabolite ratios in the equation. This confirms the dominant role of DA metabolism (i.e. increased HVA with increased $\mathrm{CB}$ ).

In contrast to the PH group where no biochemical measure related to $C B$, in the NP

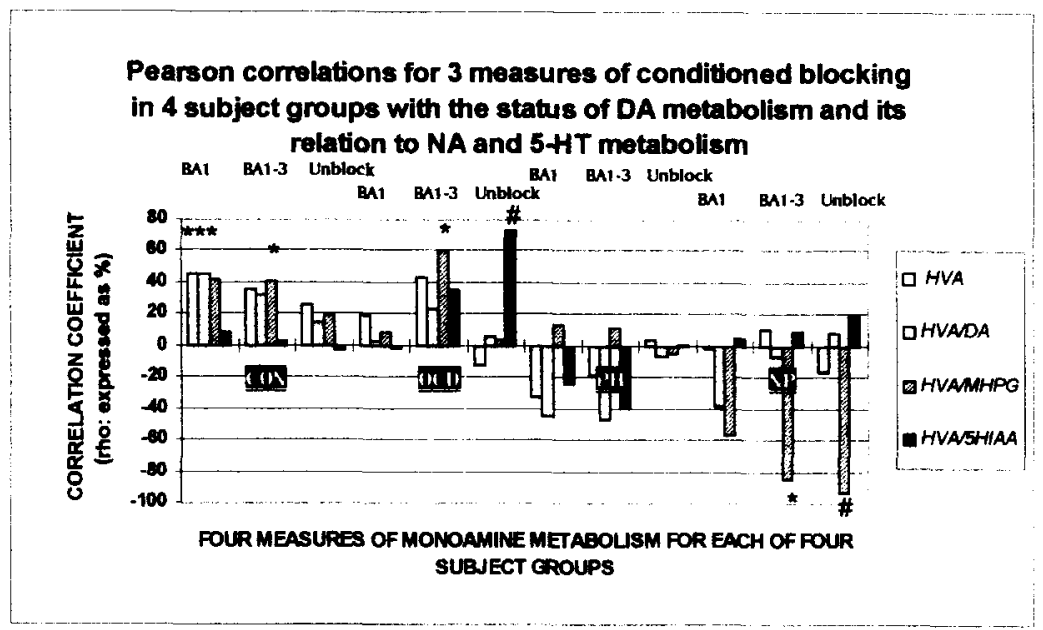

Figure 6. (Left) Early CB measures (BA 1, BA 1-3) in both comparison groups correlated positively with DA metabolism and its relation with NA metabolism $(p<.05)$. OCD patients also showed a correlation with the relation of DA to $5 \mathrm{HT}$ metabolism $(\# p<.01)$. (Right) In the NP group CB correlated negatively with the HVA/MHPG ratio ( ${ }^{*} p<.05$, \#p<.001). Correlations for $\mathrm{PH}$ patients were not significant. HVA $=1.7$ (CON, $n=29), 2.6(\mathrm{OCD}, n=11), 2.1 \quad(\mathrm{PH}, n=12), 1.7(\mathrm{NP}, n=10) \mathrm{mg} / \mathrm{mg}$ creatinine $/ \mathrm{m}^{2}$ body area. HVA $/ \mathrm{DA}$, HVA $/$ MHPG, HVA/5HIAA ratios $=9.2 / 3.6 / 10.6(\mathrm{CON}), 10.6 / 9.1 / 3.5$ (OCD), 15.8/3.7/5.2 (PH), 13.6/5.2/10.2 
patients the importance of the HVA/MHPG ratio was confirmed with MHPG and the four HVA measures in the linear regression (BA 1-3, $-.91, p=.007$; unblocking, -.98 , $p<.0001$ ). Stepwise analysis showed that although HVA and MHPG were negatively related to $\mathrm{CB}$, their ratio was dominant. Recalling that NP values for NA utilization and HVA/MHPG were higher than for controls and that $66-75 \%$ of HVA is derived from NA metabolism, the negative relationship with $\mathrm{CB}$ may be attributable to relative changes in NA rather than DA activity. The positive relationship for CB with HVA and HVA/MHPG in comparison groups may reflect the more dominant role of DA activity in their performance.

\section{Discussion}

\section{Main $C B$ results}

Normal CB was seen in healthy controls and OCD subjects. Psychotic patients taken together showed an attenuation on the first test trial-pair reflecting decreases in both $\mathrm{PH}$ and NP subgroups. Over three-five test trials NP patients continued to show less CB than either the $\mathrm{PH}$ or comparison groups. In psychotic patients extremes of negative or positive symptoms (e.g. flat-affect or bizarre behaviour) could interfere with CB. Among personality traits extroverted tendencies were beneficial in non-psychotic subjects but in those with psychosis, extremes of neuroticism or psychoticism could interfere with normal CB. Increased DA metabolism was associated with enhanced CB in both comparison groups, but a relative increase of $5 \mathrm{HT}$ metabolism in OCD patients interfered with learning about the added stimulus during testing (unblocking). A relative increase of NA vs DA activity may be associated with reduced CB in NP patients, but no clear relationship with the activity of the monoamines appeared in $\mathrm{PH}$ patients.

\section{Learning strategies and personality features}

The psychotic patients needed more trials and time to complete the task than the comparison groups, yet for healthy and patient groups alike, correlations between learning trials, exploration time and task duration were remarkably specific for each phase of each session. Further, neither the nature nor the severity of the symptoms correlated with learning measures. This is important as it implies there was no simple or artifactual explanation in terms of exposure to the task to account for group differences in CB. However, the two exceptions are informative.

First, the PH group explored the task arena for longer than the NP group. Indeed the amount of exploration shown by the PH group was remarkably similar on both sessions suggesting a stereotyped approach to the spatial constraints or context of the task. An insensitivity in adapting to where it was worth/not worth going with the cursor is consistent with the theoretical position taken by Hemsley (1987). He has interpreted the problems of information processing in patients with positive symptoms in terms of a reduced use of regularities from past experience. The $\mathrm{PH}$ strategy or cognitive style contrasts with the second feature where only the NP group showed a correlation between the number of learning trials on the two three-stimuli phases (i.e. Al and B2). This suggests a more stereotyped approach to the attentional or task demands of learning about three stimuli 
(i.e. independent of the two-stimuli B1 condition). This would lead to the prediction of more learning about the added stimulus and the attenuation of $\mathrm{CB}$. Both styles are reminiscent of the repetitive structuring of stimulus-response strategies described for chronic schizophrenics by Lyon et al. (1986) and Lyon \& Gerlach (1988).

It was this three-stimuli phase, and to an extent the $\mathrm{CB}$ result arising from it, that provided the only correlation to personality scores. The correlation implies that learning about the added stimulus (i.e. decreased CB) is more likely in the presence of neurotic traits, as suggested by Jones et al. (1990). This is consistent with reports that those with outgoing traits cope better with situations requiring parallel processing (see Introduction). This viewpoint assumes that $\mathrm{CB}$ reflects active processing of both stimuli in parallel and that reduced CB reflects shifting resources between stimuli in series. Oades et al. (1996) reported that outgoing traits in healthy adults, but not children or adolescents. correlated with the amount of CB. We were probably unable to replicate this here as our control group contained subjects selected to match patients under 16 years of age. None the less within the limited range shown by the largely introverted OCD group. CB showed a modest correlation with outgoing features.

In the PH group, neurotic lability and psychasthenia scores were high and correlated negatively with initial CB. This seems compatible with the view that these features are associated with problems of concentration and indecision (Archer, 1992, p. 194). However. it may, more specifically, relate to their insensitive exploration patterns, described above, and to impaired spatial search patterns as described by Jutai (1989) in psychosis-prone subjects. The rapid development of $\mathrm{CB}$ in the $\mathrm{PH}$ group, if difficult to explain, recalls the accelerated cognitive processing reported in an "active" group of patients with similar symptoms and personality traits by Gruzelier (1991) and Gruzelier et al. (1995). Consistent with this, our PH patients tended to show more manic features. Interestingly Gruzelier contrasted this performance with a neuropsychologically-impaired, negative, "withdrawn" group reminiscent of our NP patients.

Our correlative analysis cannot provide any evidence that attention-related performance is causally related to personality dimensions, but a number of recent studies have indicated that personality measures of psychotic-proneness and neuropsychological measures of attention-related processing may tap similar vulnerabilities (Gruzelier, 1991; Gruzelier et al., 1995; Jutai, 1989; Franke et al., 1994). Their description thus extends and adds weight to other findings of interactions between personality traits and learned inattention (see Introduction).

\section{Psvchotic symptoms}

Reflecting the symptom state of the two patient groups, the increasing presence of positive symptoms was related to less of a CB impairment. However, high or low scores on a particular symptom cluster did not mean that this was or was not important for the particular function required in the CB test. Symptoms had a differential significance for the subgroups. Thus, for PH patients bizarre behaviour (modest) and delusions (marked) were negatively, while hallucinations (marked) and thought disorder (modest) were positively, associated with $\mathrm{CB}$. Flat-affect and alogia had a generally negative association with $\mathrm{CB}$ on the first few trials, particularly in NP patients for whom symptom severity was important. 
Few studies have focused on the relation of symptoms to attentional performance. Comparisons between studies are dangerous considering the different requirements for performance and illustrate the ease of drawing incorrect inferences. Thus, thought disorder has been reported to correlate with distractibility on the digit span task (Oltmanns et al., 1978). However, in the CB task irrelevant stimuli did not catch the attention of thoughtdisordered patients; thought disorder correlated with normal CB. However, the tasks were differently set up: in the current $\mathrm{CB}$ task the stimuli were spatially separated and there was no task requirement to suppress response to the added stimulus.

In another example, Green \& Walker (1986) noted that positive symptoms and low signal detection (d-prime) related to poor digit-span performance. In the present study those with positive symptoms performed $\mathrm{CB}$ better and had better $\mathrm{d}$-prime scores than NP patients (unpublished). Indeed, as $\mathrm{CB}$ attenuation reflects learning about the stimulus in question, poor signal detection is hardly a viable explanation of NP performance.

Further, digit-span scores did not relate to poor word association performance (Allen, 1990) which required "contextual processing". This feature may be more relevant to learning about associations in the CB task than attentional span and relate to our proposal (above) on the role of perseverative learning strategies. Lubow \& Gewirtz (1995) have already posited a critical role for "context" as an "occasion setter" for eliciting learned inattention. They suggested that decreased latent inhibition in psychotic patients reflects an inability to fully use this aspect of the context or to switch from controlled to automatic processing of inconsequential events. It would be interesting to see if neuropsychological tests of frontal lobe performance, where dysfunction is implicated in poor word fluency and perseverative strategies (discussion in Elliott et al., 1995), would correlate differently with PH and NP patients' CB scores. Many studies find frontal dysfunction associated with negative symptoms (for a review see Straube \& Oades, 1992) and impaired CB has been reported in frontally damaged animals (Oades et al., 1987).

\section{The paranoid non-paranoid distinction}

We have emphasized in the previous sections the associations with symptom-cluster. This is important for two reasons. First, our subgroup distinction was based on the presence/absence of PH symptom-clusters defined by the SANS/SAPS interview. Secondly, current views on three types of schizophrenia explicitly refer to symptom-groupings and not syndromes (Liddle, 1987; Liddle et al., 1992). Thus, earlier neuropsychological studies of the performance of paranoid or non-paranoid patients were not necessarily based on the same distinction used here.

The potential usefulness of differentiating paranoid patients was recognized long ago (Kahlbaum, 1863), but the experimental study of paranoid vs non-paranoid cognitive style only really got under way 100 years later (Silverman, 1964; Magaro, 1980). These authors maintained that non-paranoid patients relied more on perceptual data and less on connotative or contextual aspects of situations to solve tasks. While more recent discussions find this view contentious (e.g. Strauss, 1993), the idea is replaced with the suggestion that positive symptoms reflect, in part, failures of automatic processing. To us this is not inconsistent with earlier formulations. Paranoid patients may be able to cope with a 
situation better than non-paranoids because they switch in an active controlled processing strategy (Heim, 1989). This explanation could underlie our finding that PH patients showed a CB impairment on the first trial, but thereafter used a normal CB strategy-through switching in controlled processing. Indeed our finding that NP patients learned more about the added stimulus could be viewed as the automatic response of a perceptual strategy. Our discussion of the "stereotyped" response of PH patients to context and of NP patients to task demands (above) also supports this distinction.

There have been numerous failures to find performance differences between paranoid and non-paranoid patients (e.g. Hoff et al., 1992; Rund et al., 1993) and yet many others that have reported "poorer" performance on psychological tests in non-paranoid vs paranoid patients (e.g. Ditchfield \& Hemsley, 1990; Neufeld \& Williamson, 1994). There is no necessary inconsistency here. If NP patients have fewer processing resources available and are more likely to use automatic processing then there are many task forms that will show an impairment. We should emphasize that in the CB task NP patients actually learned more about the added stimulus than the other groups. It is this which was unusual.

The end result is that paranoid patients may not be so deviant in co-ordinating attention (Scherer \& Storms, 1981). The difference may lie in the means they use to achieve this end. We would not take issue with Liddle's (1987) view that patients with poverty symptoms (cf. NP) are impaired in conceptual processing. In CB such an ability requires controlled parallel processing that was not an attribute of our NP patients. However, it may well be. as in other attentional tasks (Rappaport et al., 1972), that the PH patients were more able to use a normal attentional strategy than NP patients as they were more responsive to medication. We now consider this aspect in the last part of the discussion.

\section{Monoamine Activity and Medication}

\section{Medication}

Neuroleptic treatment is considered to be mildly beneficial on information processing and attention span (Spohn \& Strauss, 1989). Here we found no dose-performance relationship. However, a clinical response to neuroleptics may have been important. HVA increases implied that the PH patients were responding to medication more than the NP group and we have noted that animals treated with neuroleptics show facilitated performance on learned inattention tasks (see Introduction). The curious implication that anticholinergic medication may be beneficial for CB in 14 patients is probably an artifact as most received the same dose. Spohn \& Strauss (1989) noted that anticholinergic medication impairs recall rather than recognition processes. The latter rather than the former is important for performance of the present task.

\section{Monoamines}

It is important to note that $25-30 \%$ of HVA measured peripherally may reflect central DA metabolism with most of the remainder being derived from NA metabolism (for a review see Amin et al., 1995). Thus, as HVA/DA and HVA/MHPG ratios increased with $\mathrm{CB}$ in the control group, it is assumed that increases of DA over NA metabolism were responsible for the positive HVA/MHPG correlation. However the reverse is probably the 
case where the HVA/MHPG ratio correlated negatively with CB in the NP group. Here, in the absence of HVA/DA changes, basal MHPG/NA was nearly double that in the controls (Oades et al., 1994). Evidence for a significant role for NA metabolism in psychosis and an association with negative symptoms has been discussed at length elsewhere (e.g. Hornykiewicz, 1982; van Kammen et al., 1990; Yamamoto et al., 1994).

$\mathrm{CB}$ in the PH group was unrelated to any biochemical measure. There was evidence that this group was responding to neuroleptic medication and, in line with this, $\mathrm{CB}$ tended to normalize after the first trial-pair. This is consistent with a recent report that patients with positive symptoms show an early improvement after the onset of medication on measures of complex attention and tasks such as the Stroop test where there is a need to switch mental set (Nopoulos et al., 1994).

Together the results are consistent with our preliminary report that higher DA activity was found in subjects showing normal CB (Oades et al., 1992). However, they show that it would be more precise to say that, within limits, relative increases of DA utilization are associated with increasing CB and not that CB is predicted by high DA turnover, per se. The results are also consistent with animal studies showing that acute neuroleptic treatment facilitates latent inhibition (Feldon \& Weiner, 1991).

A plausible interpretation of these data refers to a putative function of DA activity in switching and NA activity in tuning (Oades, 1985). Basically this suggests that DA activity promotes the likelihood that there will be a change from the input to a given brain area that predominantly controls the output of this area. Increased NA activity is involved in tuning between the inputs competing in a given brain area to influence the output. Low DA activity (less switching) and high NA activity (overtuning) could lead to an inflexibility of response. This leads to persistence of the ongoing set or strategy and may be illustrated by the CB performance of NP patients. In contrast PH patients are more able to switch setlike controls (cf. Nopoulos et al., 1994, above). Perhaps the benefit of increased DA activity in controls is seen in the proposal of Lubow \& Gewirtz (1995) whereby the ability to switch between controlled and automatic processing of inconsequential events is promoted.

Could the subgroup differences reported here reflect more frontal dysfunction in the NP group? Siever (1994) noted that the incidence of deficit symptoms in schizotypal patients correlated with decreased peripheral measures of HVA that in turn correlated negatively with the performance of tests said to reflect frontal function. The hippocampus and associated limbic areas are involved in mediating learned inattention in rats (see Introduction); however, there is a body of evidence suggesting that a number of attention-related effects in primates are taken over by the frontal lobe (e.g. Oades, 1982, pp. 123-128). Indeed, recently normal latent inhibition performance was reported in patients with temporal lobe epilepsy, implying that mesial temporal lobe structures may not mediate learned inattention in man (Gray et al., 1995). Hence as Siever (1994) reported enlarged ventricles and altered PET measures of frontal metabolism in neuropsychologically impaired schizotypal patients, it would be instructive to study neuropsychological performance and tomographic measures of atrophy and metabolism in patients with a known CB impairment. 
Altree-Williams and E. Kuske for programming assistance. We are also grateful to Professor G. Sartory, Dr $\mathbf{S}$. Bender and Dr U. Schall for their discussions and for financial support from the German research council (DFG OA $1 / 4-1)$.

\section{References}

Ackil, J. E., Mellgren, H. C., Halgren, C., \& Frommer, G. P. (1969). Effects of CS preexposure on avoidance learning in rats with hippocampal lesions. Journal of Comparative and Physiological Psychology, 69, 739-747.

Allen, H. A. (1990). Cognitive processing and its relationship to symptoms and social functioning in schizophrenik. British Journal of Psychiatry, 156, 201-203.

Amin, F., Davidson, M., Kahn, R. S., Scheidler, J., Stern, R., Knott, P. J., \& Apter, S. (1995). Assessment of the central dopaminergic index of plasma HVA in schizophrenia. Schizophrenia Bulletin, 21, 53-66.

Andreasen. N. C. (1983). The scale for the assessment of negative simptoms (SANS). lowa City. IA: University of Iowa Press.

Andreasen, N. C. (1984). The scale for assessment of positive symptoms (SAPS). Iowa City. IA: University of Iowa Press.

Archer, R. P. (1992). MMPI-A: Assessing adolescent psychopathology. Hillsdale, NJ: Lawrence Erlbaum.

Baruch, I., Hemsley, D. R., \& Gray, J. A. (1988). Latent inhibition and "psychotic proneness" in normal subjects Personality and Individual Differences, 9, 777-783.

Baruch, I., Hemsley, D. R., \& Gray, J. A. (1988). Differential performance of acute and chronic schizophrenics in a latent inhibition task. Journal of Nervous and Mental Disease, 176, 598-606.

Buggle, F. \& Baumgürtel, F. (1975). Hamburger Neuroticismus- und Extroversionsskala für Kinder und Jugendliche (HANES, KJ). Göttingen: Hogrefe.

Cassaday, H. J., Mitchell, S. N., Williams, J. H., \& Gray, J. A. (1993). 5,7-dihydroxytryptamine lesions in the fornix-fimbria attenuate latent inhibition. Behavioral and Neural Biology, 59, 194-207.

Caza, P. A. (1984). Noradrenergic influences on blocking: interactions with development. Pharmacologl', Biochemistry and Behavior, 21, 9-17.

Crider, A., Blockel, L., \& Solomon, P. R. (1986). A selective attention deficit in the rat following induced dopamine receptor supersensitivity, Behavioral Neuroscience, 100, 315-319.

Crider, A., Solomon, P. R., \& McMahon, M. A. (1982). Disruption of selective attention in the rat following damphetamine administration: relationship to schizophrenic attention disorder. Biological Psychiatry. 17, 35i 361 .

De la Casa, L. (I., Ruiz, G., \& Lubow, R. E. (1993). Latent inhibition and recall/recognition of irrelevant stimuli as a function of preexposure duration in high and low psychotic prone normal subjects. British Journal of Psychology, 84, 119 $\cdots 132$.

Ditchfield, H., \& Hemsley, D. R. (1990). Interhemispheric transfer of information and schizophrenia. European Archives of Psychiatry and Neurological Sciences, 239, 309-313.

Eggers, C. (1968). Zwangszustände und schizophrenie. Fortschritte der Neurologie und Psychiatrie, 36, 576 589.

Eisen, J. L.. \& Rasmussen, S. A. (1993). Obsessive compulsive disorder with psychotic features. Journal of (linisal Psychiatry, 54, 373-379.

Elliott, R., McKenna, P. J., Robbins, T. W., \& Sahakian, B. J. (1995). Neuropsychological evidence for frơntostriatal dysfunction in schizophrenia. Psychological Medicine, 25, 619-630

Eysenck, M. W. (1982). Attention and arousal: cognition and performance. Berlin: Springer.

Feldon. J.. \& Weiner. I. (1991). The latent inhibition model of schizophrenic attention disorder: haloperidol and sulpiride enhance rat's ability to ignore irrelevant. stimuli. Biological Psychiatry, 29, 635-646.

Franke, P., Maier, W., Hardt, J., Hain, C. \& Cornblatt, B. A. (1994). Attentional abilities and measures of schizotypy: their variation and covariation in schizophrenic patients, their siblings and normal control subjects Psychiatry Research, 54, 259-272.

Gehring, A. \& Blaser, A. (1982). Minnesota multiphasic personality imentory (MMPI): DI. Kurzform für Handauswertung; Handbuch. Bern: Huber.

Gray, J. A., Feldon, J., Rawlins, J. N. P., Hemsley, D., \& Smith, A. (1990). The neuropsychology of schizophrenia. Behavioral Brain Sciences, 14, 1-84.

Gray, N. S., Hemsley, D. R., \& Gray, J. A. (1992). Abolition of latent inhibition in acute but not in chronic schizophrenics. Neurology, Psychiatry and Brain Research, 1, 8389.

Gray, N. S.. Mellers, J. D. C., Morton, N., Hemsley, D. R., Goldstein, L. H., \& Toone, B. K. (1995). Latent inhibition in temporal lobe epilepsy and the schizophrenia-like psychoses of epilepsy. Schizophrenia Researkh, 15,177 
Green, M. F., \& Walker, E. F. (1986). Attentional performance in positive- and negative-symptom schizophrenia. Journal of Nervous and Mental Diseases, 174, 208-213.

Gruzelier, J. H. (1991). Hemispheric imbalance: syndromes of schizophrenia, premorbid personality and neurodevelopmental influences. In S. Steinhauer, J. Gruzelier \& J. Zubin (Eds), Handbook of schizophrenia. IV. Experimental psychopathology, neuropsychology and psychophysiology (pp. 599-650). Amsterdam: Elsevier.

Gruzelier, J. H., Burgess, A., Stygall, J., Irving, G., \& Raine, A. (1995). Patterns of cognitive asymmetry and syndromes of schizotypal personality. Psychiatry Research, 56, 71-79.

Heim, G. (1989). Attentional functions in listening and schizophrenia: a selective review. European Archives of Psychiatry and Neurological Sciences, 239, 62-69.

Hemsley, D. R. (1987) An experimental psychological model for schizophrenia. In H. Häfner, W. F. Gattaz \& W. Janzarik (Eds), Search for the causes of schizophrenia (pp. 179-188). Berlin: Springer.

Hoff, A. L., Riordan, H., O'Donnell, D. W., Morris, L., \& De Lisi, L. E. (1992). Neuropsychological functioning of first-episode schizophreniform patients. American Journal of Psychiatry, 149, 898-903.

Honey, R. C., \& Good, M. (1993). Selective hippocampal lesions abolish the contextual specificity of latent inhibition and conditioning. Behavioral Neuroscience, 107, 23-33.

Hornykiewicz, O. (1982). Brain catecholamine in schizophrenia-a good case for noradrenaline. Nature, 299, $484-486$.

Insel, T. R. (1992). Toward a neuroanatomy of obsessive-compulsive disorder. Archives of General Psychiatry, 49, $739-744$.

Jones, S. H., Gray, J. A., \& Hemsley, D. R. (1990). The Kamin blocking effect, incidental learning and psychoticism. British Journal of Psychology, 81, 95-110.

Jones, S. H., Gray, J. A., \& Hemsley, D. R. (1992). Loss of the Kamin blocking effect in acute but not chronic schizophrenics. Biological Psychiatry, 32, 739-755.

Jutai, J. W. (1989). Spatial attention in hypothetically psychosis prone college students. Psychiatry Research, 27, $207-211$

Kahlbaum, K. (1863). Die Gruppierung der psychischen Krankheiten. Danzig: Kafemann.

Kamin, L. J. (1969). Predictability, surprise, attention and conditioning. In R. Church \& B. Campbell (Eds), Punishment and aversive behavior (pp. 279-296). New York: Appleton-Century-Crofts.

Liddle, P. F. (1987). Schizophrenic syndromes, cognitive performance and neurological dysfunction. Psychological Medicine, 17, 49-57.

Liddle, P. F., Friston, K. J., Frith, C. D., Hirsch, S. R., Jones, T. \& Frackowiak, R. S. J. (1992). Patterns of cerebral blood flow in schizophrenia. British Journal of Psychiatry, 160, 179-186.

Linnoila, M., Virkkunen, M., Scheinin, M., Nuutila, A., Rimon, R., \& Goodwin, F. K. (1983). Low cerebrospinal fluid 5-hydroxyindoleacetic acid concentration differentiates impulsive from nonimpulsive violent behavior. Life Sciences, 33, 2609-2614.

Lipp, O. V., \& Vaitl, D. (1992) Latent inhibition in human Pavlovian differential conditioning: effect of additional stimulation after preexposure and relation to schizotypal traits. Personality and Individual Differences, 13, 10031012.

Lorden, J. F., Rickert, E. J., \& Pelleymounter, M. A. (1980). Forebrain norepinephrine and the selective processing of information. Brain Research, 190, 569-573.

Lubow, R. E., \& Gewirtz, J. C. (1995). Latent inhibition in humans: data, theory and implications for schizophrenia. Psychological Bulletin, 117, 87-103.

Lubow, R. E., Inberg-Sachs, Y., Zalstein-Orda, N., \& Gewirtz, J. C. (1992). Latent inhibition in low and high "psychotic prone" normal subjects. Personality and Individual Differences, 13, 563-572.

Lubow, R. E., \& Moore, A. U. (1959). Latent inhibition: the effect of nonreinforced preexposure to the conditioned stimulus. Journal of Comparative and Physiological Psychology, 52, 415-419.

Lubow, R. E., Weiner, I., Schlossberg, A., \& Baruch, I. (1987). Latent inhibition and schizophrenia. Bulletin of the Psychonomic Society, 25, 464-467.

Lyon, N., \& Gerlach, J. (1988). Perseverative structuring of responses by schizophrenic and affective disorder patients. Journal of Psychiatric Research, 22, 261-277.

Lyon, N., Mejsholm, B., \& Lyon, M. (1986). Stereotyped responsing by schizophrenic outpatients: cross-cultural confirmation of perseverative switching on a two-choice task. Journal of Psychiatric Research, 20, $137-150$.

Magaro, P. A. (1980). Cognition in schizophrenia and paranoia: the integration of cognitive processes. Hillsdale, NJ: Erlbaum.

Merritt, R. D., \& Balogh, D. W. (1990). Backward masking as a function of spatial frequency: a comparison of MMPI-identified schizotypics and control subjects. Journal of Nervous and Mental Disease, 178, $186-193$.

Mohammed, A. K., Callenholm, N. E. B., Järbe, T. U. C., Swedberg, M. D. B., Danysz, W., Robbins, T. W., \& Archer, T. (1986). Role of central noradrenaline neurons in the contextual control of latent inhibition in taste aversion learning. Behavioral Brain Research, 21, 109-118. 
Neufeld, R. W. J., \& Williamson, P. C. (1994). Neuropsychological correlates of positive symptoms: delusions and hallucinations. In C. Pantelis, H. Nelson \& T. Barnes (Eds), The neuropsychology of schizophrenia (p. 29). London: Wiley.

Nopoulos, P., Flasman, L., Flaum, M., Arndt, S., \& Andreasen, N. C. (1994). Stability of cognitive functioning early in the course of schizophrenia. Schizophrenia Research, 14, 29-37.

Oades, R. D. (1982). Attention and schizophrenia; neurobiological bases. London: Pitman Press.

Oades, R. D. (1985). The role of noradrenaline in tuning and dopamine in switching between signals in the CN\$ Neuroscience and Biobehavioral Reviews, 9, $261-283$.

Oades, R. D., Bunk, D., \& Eggers, C. (1992). Paranoid schizophrenics may not use irrelevant signals: the use of measures of blocking and of urinary dopamine. Acta Paedopsychiatrica, 55, 183-184.

Oades, R. D., Rivet, J.-M., Taghzouti, K., Kharouby, M., Simon, H., \& Le Moal, M. (1987). Attentional blocking is delayed by depletion of septal dopamine but remains attenuated after frontal depletion. Brain Research, 406 , $136-146$.

Oades, R. D., Roepcke, B., \& Eggers, C. (1994). Monoamine activity reflected in urine of young patients with obsessive compulsive disorder, psychosis with and without reality distortion and healthy subjects: an explorative analysis. Journal of Neural Transmission, 96, 143-159.

Oades, R. D., Roepcke, B., \& Schepker, R. (1996). A test of conditioned blocking and its development in childhood and adolescence: relationship to personality, and monoamine metabolism. Developmental Neuropsychologl: 12

Oltmanns, T. F., Ohayon, J., \& Neale, J. M. (1978). The effect of antipsychotic medication and diagnostic criteria on distractibility in schizophrenia. Journal of Psychiatric Research, 14, 81-91.

Overall, J. E., \& Gorham, D. R. (1962). The Brief Psychiatric Rating Scale. Psychological Reports, $10,799-812$.

Rappaport, M.. Hopkins, H. K., Silverman. J.. \& Hall. K. (1972). Auditory signal detection in schizophrenics. Psychopharmacolog $1,24,6-28$.

Reed, G. F. (1985). Obsessional experience and compulsite behatior. A coynitice structural approach. London Academic Press.

Rey, M. J., Schulz. P., Costa, C., Dick, P., \& Tissot, R. (1989). Guidelines for the dosage of neuroleptics, 1: Chlorpromazine equivalents of orally administered neuroleptics. International Clinical Psychophamatolog!, 4, 95-104.

Rickert, E. J., Bennett, T. L., \& Lane, P., Fench. J. (1978). Hippocampectomy and the attenuation of blocking. Behavioral Biology, 22, 147-160.

Rund, B. R., Landro, N. 1.. \& Orbeck, A. L. (1993). Stability in backward masking performance in schizophrenids. affectively disturbed patients and normal subjects. Journal of Nervous and Mental Disease, 181, 223.237.

Schalling, D., Asberg, M., Edman, G., \& Levander, S. (1984). Impulsivity, nonconformity and sensation seeking as related to biological markers for vulnerability. Clinical Neuropharmacology, 7(1), 746-747.

Scherer, M., \& Storms, L. (1981). Attention and visual reaction time in schizophrenia. Journal of Nerrous and Mental Disease, 169, 348--356.

Schmajuk, N. A.. Lam, Y.-W., Christiansen, B.A. (1994). Latent inhibition of the rat eyeblink response: effect of hippocampal aspiration lesions. Physiology and Behavior, 55, 597-601

Shakow, D. (1936). Mental set in schizophrenia studied in a discrimination reaction setting. Psychological Bullerin. 33, $795 \cdot 796$.

Siever, L. J. (1994). Biologic factors in schizotypal personal disorders. Acta psychiatrica scandinatica. 90 (suppl. 384), 45-50

Silverman, J. (1964). Variations in cognitive control and psychophysiological defense in the schizophrenias. Psychosomatic Medicine, 29, 225-251.

Solomon. P. R. (1977). Role of the hippocampus in blocking and conditioned inhibition of the rat's nictitating membrane response. Journal of Comparative and Physiological Psycholog1, 91, 407-417.

Solomon, P. R., Crider, A., Winkelman, J. W., Turi, A., Kamer, R. M.. \& Kaplan, L. J. (1981). Disrupted latent inhibition in the rat with chronic amphetamine or haloperidol-induced supersensitivity: relationship to schizophrenic attention disorder. Biological Psychiatry, 16, $519-537$.

Solomon. P. R. Kiney, C. A., \& Scott, D. R. (1978). Disruption of latent inhibition following systemic administration of parachlorophenylalanine (PCPA). Physiology and Behavior, 20, 265-271.

Solomon, P. R., Nichols, G. L., Kiernan, J. M., Kamer, R. S., \& Kaplan, L. J. (1980). Differential effects of lesions in medial and dorsal raphe of the rat: latent inhibition and septohippocampal serotonin levels. Jourhal of Comparative and Physiological Psychology, 94, $145-154$.

Solomon, P. R., \& Staton, D. M. (1982). Differential effects of microinjections of d-amphetamine into the nucleus accumbens or the caudate-putamen in the rat's ability to ignore an irrelevant stimulus. Biological Psichiatry. 17, 743-756.

Spohn, H. E., \& Strauss, M. E. (1989). Relation of neuroleptic and anticholinergic medication to cognitive functions in schizophrenia. Journal of Abnormal Psychology. 98, 367-380 
Straube, E. R., \& Oades, R. D. (1992). Schizophrenia: empirical research and findings. New York: Academic Press. Strauss, M. E. (1993). Relations of symptoms to cognitive deficits in schizophrenia. Schizophrenia Bulletin, 19, $215-231$.

Swerdlow, N. R., Filion, D. L., Geyer, M. A., \& Braff, D. L. (1995). "Normal" personality correlates of sensorimotor, cognitive and visuospatial gating. Biological Psychiatry, 37, 286-299.

Tai, C.-T., Cassaday, H. J., Feldon, J., \& Rawlins, J. N. P. (1995). Both electrolytic and excitotoxic lesions of nucleus accumbens disrupt latent inhibition in rats. Neurobiology of Learning and Memory, 64, 36 48.

van Kammen, D. P., Peters, J., Yao, J. K., van Kammen, W. B., Neylan, T., Shaw, D., \& Linnoila, M. (1990). Norepinephrine in acute exacerbations of chronic schizophrenia: negative symptoms revisited. Archives of General Psychiatry, 47, 161-168.

Weiner, I., Lubow, R. E., \& Feldon, J. (1988). Disruption of latent inhibition by acute administration of low doses of amphetamine. Pharmacology, Biochemistry and Behavior, 30, 871-878.

Yamamoto, K.-I., Ozawa, N., Shinba, T., Hshino, T., \& Yoshii, M. (1994). Possible noradrenergic dysfunction in schizophrenia. Brain Research Bulletin, 35, 529-543. 